\title{
EXPERIENCE AND KNOWLEDGE OF PAIN MANAGEMENT IN CANCER OUTPATIENTS: IMPLICATIONS FOR PRACTICE
}

\author{
Li-Lu Chang, DNP, RN; Min-Wen Liao, MSN, RN \\ Center for Advancement of Nursing Education \\ Koo Foundation Sun Yat-Sen Cancer Center, Taipei, Taiwan
}

\section{Background}

Cancer pain influences psychological and social functioning and vice versa. The direct association between pain and patients' quality of life highlight the importance of effective pain management. However, management of cancer pain is considered to be complex. In spite of the existing practice guidelines and knowledge for effective pain management, a big proportion of cancer patients are still treated inadequately for pain. Under-treatment of pain is particular important for ambulatory oncology patients with advanced diseases.

\section{Objectives}

The aim of this study is to explore cancer outpatients' knowledge and experiences for pain management at home.

\section{Methods}

This is a prospective, cross-sectional study of cancer patients who were seen at outpatient clinics in a cancer center in Taipei, Taiwan. Brief Pain Inventory (BPI), Pain Management Index (PMI), and Morisky Medication Adherence Scale (MMAS) were administered to measure pain intensity, pain management quality, adherence for pain medication, and knowledge and experience of patients in managing cancer pain.

\begin{tabular}{|c|c|c|c|c|c|c|}
\hline \multicolumn{3}{|c|}{ Age (in years) } & $\begin{array}{r}\text { Mean } \pm S \\
53.11 \pm 10\end{array}$ & \multicolumn{3}{|c|}{$\begin{array}{c}\text { Median (range) } \\
52(26-80)\end{array}$} \\
\hline & & & $\mathrm{n}$ & & $\%$ & \\
\hline \multicolumn{7}{|l|}{ Sex } \\
\hline \multicolumn{3}{|l|}{ Male } & 54 & & 66.67 & \\
\hline \multicolumn{3}{|l|}{ female } & 27 & & 33.33 & \\
\hline \multicolumn{7}{|c|}{ Education Level } \\
\hline \multicolumn{3}{|c|}{ Elemental school } & 10 & & 12.35 & \\
\hline \multicolumn{3}{|c|}{ Junior high school } & 13 & & 16.05 & \\
\hline \multicolumn{3}{|c|}{ Senior high school } & 37 & & 45.68 & \\
\hline \multicolumn{3}{|c|}{ College and above } & 21 & & 25.92 & \\
\hline \multicolumn{7}{|c|}{ Primary Cancer Site } \\
\hline \multicolumn{3}{|c|}{ Oral or Nasopharyngeal } & 29 & & 35.80 & \\
\hline \multicolumn{3}{|c|}{ Lung } & 11 & & 13.58 & \\
\hline \multicolumn{3}{|l|}{ Esophagus } & 10 & & 12.35 & \\
\hline \multicolumn{3}{|c|}{ Pancreas, bile duct or liver } & 10 & & 12.35 & \\
\hline \multicolumn{3}{|c|}{ Colon- rectum } & 9 & & 11.11 & \\
\hline \multicolumn{3}{|l|}{ Breast } & 3 & & 3.70 & \\
\hline \multicolumn{3}{|l|}{ Stomach } & 3 & & 3.70 & \\
\hline \multicolumn{3}{|c|}{ Hematologic } & 2 & & 2.47 & \\
\hline \multicolumn{3}{|c|}{ Others } & 4 & & 4.94 & \\
\hline \multicolumn{7}{|l|}{ Metastasis } \\
\hline \multicolumn{3}{|l|}{ Yes } & 40 & & 49.40 & \\
\hline \multicolumn{3}{|l|}{ No } & 41 & & 50.60 & \\
\hline \multicolumn{7}{|c|}{ Current Treatments } \\
\hline \multicolumn{3}{|l|}{ CCRT } & 37 & & 45.68 & \\
\hline \multicolumn{3}{|c|}{ Chemotherapy } & 37 & & 45.68 & \\
\hline Symptom 1 & anag & ment & 7 & & 8.64 & \\
\hline Types of Pre & cribe & Analgesics & & & & \\
\hline Strong opi & & & 54 & & 66.67 & \\
\hline Weak opio & & & 27 & & 33.33 & \\
\hline $\begin{array}{l}\text { Pain with ne } \\
\text { characteristi }\end{array}$ & $\begin{array}{l}\text { roge } \\
\text { s }\end{array}$ & & & & & \\
\hline Yes (S-LA) & $\mathrm{SS}>$ & 12) & 37 & & 45.68 & \\
\hline No (S-LAI & $\mathrm{SS}<$ & 12) & 44 & & 54.32 & \\
\hline Table 2 & The & listribution of & MI and pa & score $(\mathrm{N}$ & $\mathrm{N}=81)$ & \\
\hline & & & PMI & & & \\
\hline Pain Score & -3 & -2 & 0 & 1 & 2 & 3 \\
\hline 0 & 0 & 0 & 0 & 0 & $1(1 \%)$ & $2(2 \%)$ \\
\hline $\begin{array}{c}1-3 \\
\text { Mild pain }\end{array}$ & 0 & 0 & 0 & $5(6 \%)$ & $7(9 \%)$ & 0 \\
\hline $\begin{array}{c}4-7 \\
\text { Moderate pain }\end{array}$ & 0 & 0 & $15(19 \%)$ & $24(30 \%)$ & 0 & 0 \\
\hline $\begin{array}{c}8-10 \\
\text { Severe pain }\end{array}$ & 0 & $6(7 \%)$ & $21(26 \%)$ & 0 & 0 & 0 \\
\hline
\end{tabular}

\section{Results}

Eighty-one patients with advanced cancer diseases have participated in this study (Table 1). $83 \%$ of patients' report of the worst pain in 24 hours was moderate and severe (Fig 1). More than $60 \%$ of the patient's report of interference with daily function was from moderate to severe (Fig 2). Of 36 patients whose PMI scores $=0,36(100 \%)$ patients' report of worst pain in the past 24 hours was moderate to severe. (Table 2). Bivariate analysis found that patients' $\mathrm{PMI}$ and worst pain severity was directly related to pain interference scores. The mean pain interference score measured by BPI was 5.11 with SD of 2.91 (range from 0 to 10 ); in which subscale scores the mean affective interference score is higher than activity interference score $(5.23+3.19$ vs. $4.69+2.91$ ). About $85 \%$ of these patients were in the category of low and moderate pain-medication adherence which was measured by the MMAS.

\section{Implications for Practice}

Cancer outpatients have to manage their pain at home on a daily basis. Our results identify the need to incorporate patientreported outcomes in the assessment and treatment of cancer pain in the outpatient settings. The results may also highlight the importance of self-management support to enable patients in managing their pain at home.

Fig 1. Patients' report of pain severity in the last 24 hours

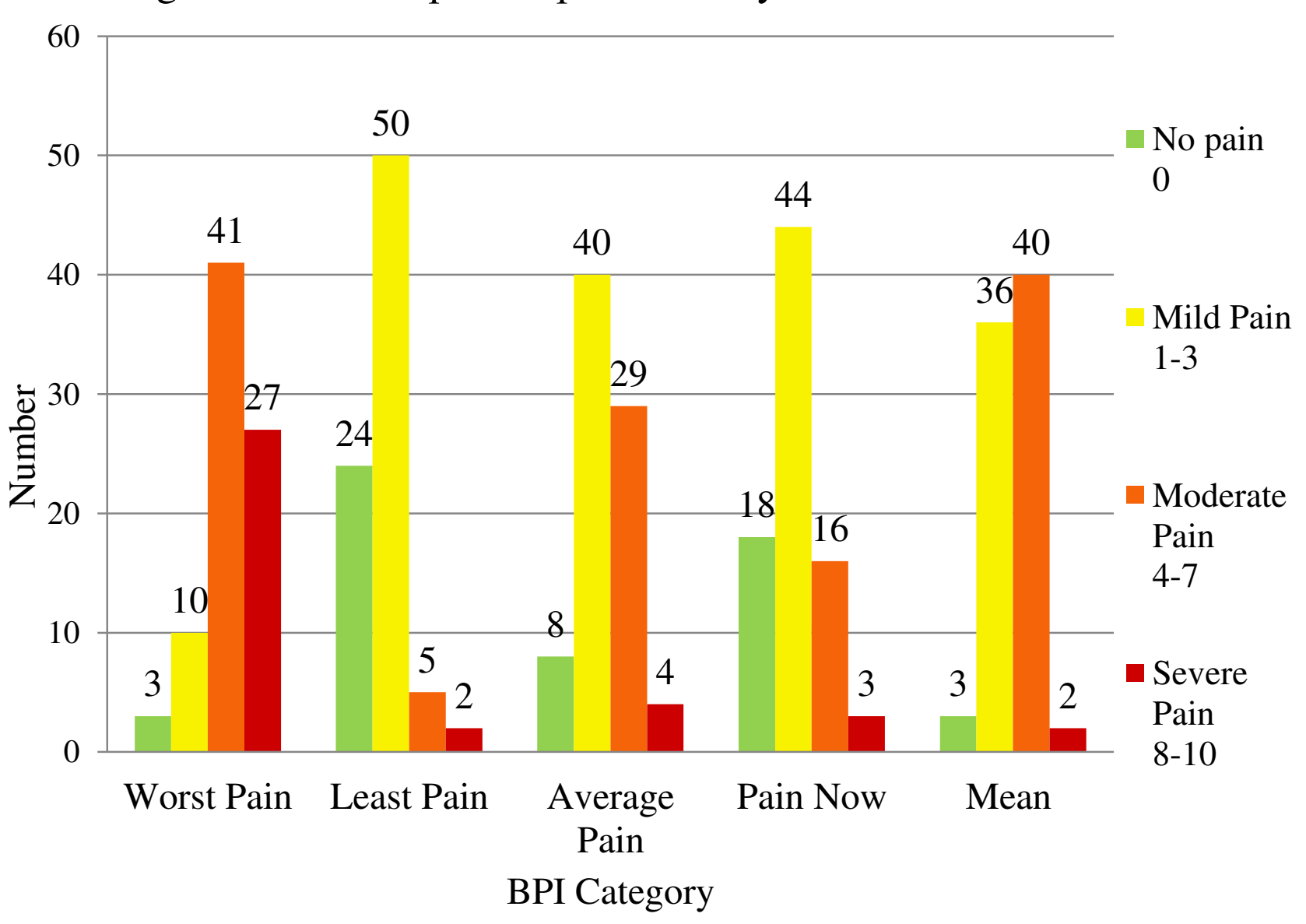

Fig 2. Patients' report of pain interference score in the last 24 hours

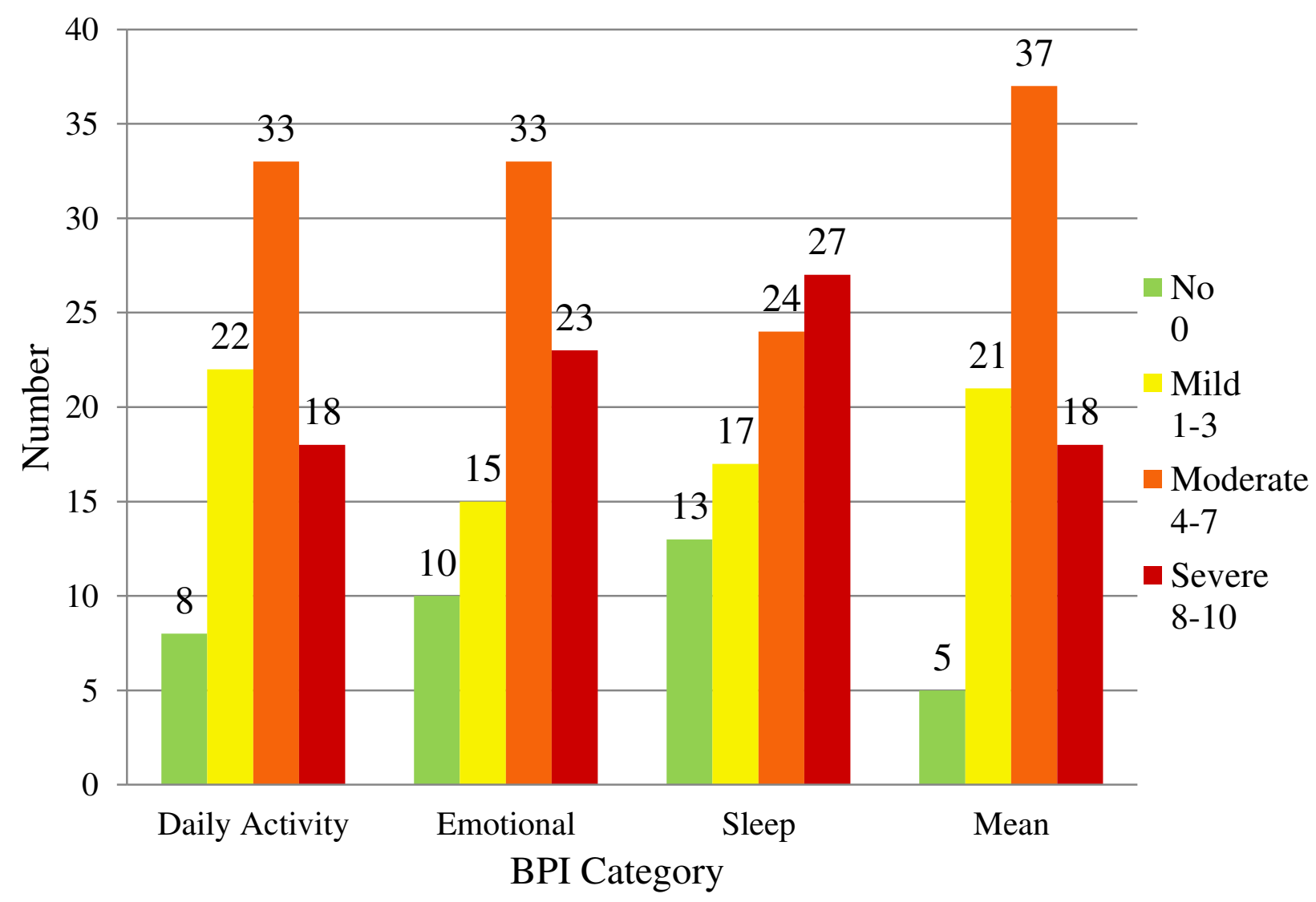

